\title{
Evaluation of immobilization in external rotation after primary traumatic anterior shoulder dislocation: 5-year results
}

\author{
M. Königshausen • B. Schliemann • T. A. Schildhauer • \\ D. Seybold
}

Received: 11 January 2013/Accepted: 22 May 2013/Published online: 5 June 2013

(C) Istituto Ortopedico Rizzoli 2013

\begin{abstract}
Background It is still not clear which method is the most efficient for treating primary traumatic anterior shoulder dislocation. Immobilization in external rotation has become increasingly discussed within the last 10 years. The aim of this study was to evaluate the rate of recurrence and clinical outcome of the immobilization in external rotation after primary traumatic anterior dislocation within a midterm period of 5 years. Additionally, a summary of literature is given according to the present knowledge of this issue.

Methods From May 2004 to May 2006, 28 patients with primary traumatic anterior shoulder dislocations were included in a prospective MRI-controlled study. After a follow-up of 5 years, the recurrence rate and clinical outcomes of the patients were evaluated using clinical scores (Constant and Murley score, Western Ontario Shoulder Instability Index, Rowe score).
\end{abstract}

M. Königshausen ( $\square)$ · T. A. Schildhauer · D. Seybold

Department of General and Trauma Surgery, BG

Universitätsklinikum Bergmannsheil, Ruhr-Universität Bochum,

Bürkle-de-la-Camp-Platz 1, 44789 Bochum, Germany

e-mail: matthias.koenigshausen@gmail.com;

m.koenigshausen@web.de

T. A. Schildhauer

e-mail: thomas.a.schildhauer@rub.de

D. Seybold

e-mail: dseybold@mac.com

\section{B. Schliemann}

Department of Trauma-, Hand- and Reconstructive Surgery,

Universitätsklinikum Münster, Waldeyerstraße 1,

48148 Münster, Germany

e-mail: benedikt.schliemann@gmail.com
Results After 5 years, 26 patients (93\%; males, $n=25$; female, $n=1$; mean age, 29.3 years) were interviewed concerning re-dislocations. In the meantime, four patients (15\%) experienced a re-dislocation ( $\phi 12.2$ months) after the end of the immobilization. Overall, 21 patients $(75 \%)$ were included in a clinical follow-up (CM score: $\phi 92.8$ points; Western Ontario Shoulder Instability Index: $\phi$ $87 \%$; Rowe score (in 17 patients): $\phi 94.2$ points). Upon clinical examination, unidirectional anterior instability was found in one patient, which corresponds to an overall instability rate of $19 \%$ within the examined patient population including the re-dislocations.

Conclusions Immobilization in external rotation shows satisfactory results after 5 years in regard to recurrence and instability rates and clinical outcomes. The data show that with immobilization in external rotation, re-dislocations occur within the first 2 years.

Keywords Shoulder dislocation - Non-operative treatment · Immobilization - External rotation · Bankart lesion

\section{Introduction}

In 1999, Itoi et al. [1] were the first to hypothesize a new method of immobilization for a first-time traumatically dislocated shoulder. Based on a cadaver study, they reported that external rotation of the shoulder with tightening of the anterior soft tissues was able to bring a labrum lesion into a better position on the antero-inferior glenoid. With external rotation of the arm, the anterior capsule and the subscapularis tendon pull the medially displaced labrum laterally onto the glenoid rim. In comparison with traditional immobilization in internal rotation, this new 
method was assumed to reduce the recurrence rate after a first-time traumatic anterior shoulder dislocation. These findings were later supported by Itoi et al. [2, 3] in an MRI study (2001) and in a randomized controlled study (2007) in which a significantly lower recurrence rate could be found in patients who were initially treated with an external rotation brace $(20 \%$ recurrence rate in the external rotation group vs. $38 \%$ in the internal rotation group). Several other studies have been published since the initial reports by Itoi et al., investigating the immobilization period [4] and the amount of external rotation that is required to effectively reduce the labroligamentous complex (LLC) [5].

Consistent with two prospective randomized studies, the potential of external rotation to significantly reduce the recurrence rate compared with the classical immobilization in internal rotation method came into question within the last 3 years [6, 7]. Recently, data published by Liavaag et al. found no advantage of external rotation in the recurrence rate in comparison with patients treated with an internal rotation brace [7].

Given the inconsistent conclusions from the literature, the aim of the present study was to investigate the recurrence and instability rates of patients 5 years after primary traumatic anterior shoulder dislocation treated with an external rotation brace in our institution between 2004 and 2006. Furthermore, clinical examination and different clinical scores were used to record the condition of the affected shoulder in terms of function and stability. For the first time, midterm results for external rotation after primary traumatic dislocation are presented in the underlying prospective study and will be discussed in conjunction with the actual level of knowledge of this subject.

\section{Patients and methods}

Between May 2004 and May 2006, 29 patients with a firsttime traumatic anterior shoulder dislocation were enrolled in a prospective MRI-controlled study (Fig. 1). A necessary criterion was an anterior primary traumatic shoulder dislocation without hyperlaxity (B2 by Gerber [8]) or previous instability of the contralateral side. Exclusion criteria were concomitant bony injuries, such as fractures of the proximal humerus, scapula or glenoid (bony Bankart lesion, Bankart fracture), or lesions of surrounding or intra-articular soft tissues, such as rotator cuff tears. Also, patients with medical histories of previous injuries at the affected shoulder were excluded. The patients' ages ranged between 15 and 45 years. An interval between trauma and immobilization in external rotation of more than 14 days and an immobilization period $<3$ weeks were exclusion criteria. At the time of the 5-year follow-up examination, one patient (male, 42 years) admitted to non-compliance. He discontinued the immobilization before the end of 3 weeks because of limitations in his daily life and was thus excluded from the study ( $n=28$ patients remaining). Additionally, three patients were not invited for follow-up examination because of a re-dislocation and subsequent arthroscopic surgery of the affected shoulder in the interim (see below).

According to a standardized protocol, patients were clinically examined after traumatic shoulder dislocation and radiographs in two planes were obtained before and after reduction (AP before reduction, AP and axial view after reposition). Afterward, hyperlaxity of the contralateral unaffected shoulder was evaluated, and an ultrasound was performed on the dislocated shoulder to exclude rotator cuff lesions. All patients were scheduled to the shoulder clinic for an external rotation brace adjustment and were assigned to take the brace off only for personal hygiene. Within 14 days after dislocation, a standard MRI scan (Siemens Symphony 1.5 Tesla, axial, coronal, sagittal planes: plane thickness: $3 \mathrm{~mm}$ ) of the affected shoulder in internal rotation was performed. If an LLC lesion was detected, the shoulder was brought into a maximum tolerated external rotation position (at least $10^{\circ}$ ) for additional axial planes (Fig. 2). According to the method described by Itoi et al. [2], the position of the LLC was measured using the axial MRI planes at the level of maximum medial dislocation (D) and the maximum anterior separation (S) (in millimeters) relative to the glenoid rim (Fig. 3). Immediately after the MRI investigation, all shoulders were immobilized with an external rotation brace (Ultrasling $^{\circledR}$, Fa. Donjoy, Vista, CA, USA) between $15^{\circ}$ and $30^{\circ}$ external rotation for 3 weeks. Six weeks after trauma,

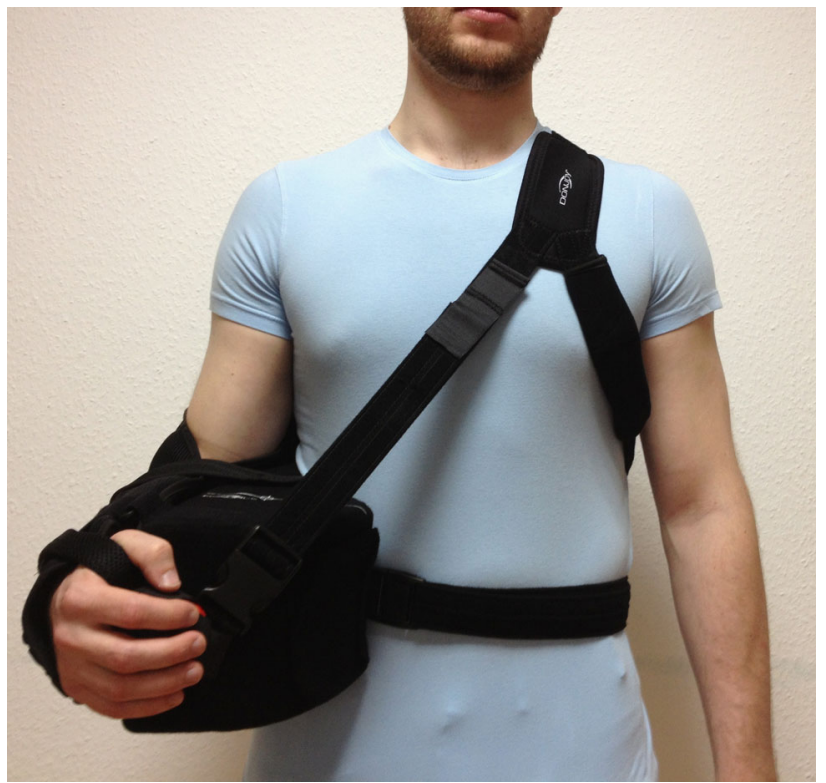

Fig. 1 Patient with the right shoulder immobilized in external rotation after primary traumatic shoulder dislocation 
a second MRI scan in internal rotation was performed in 23 patients $(82 \%)$ to re-investigate dislocation (D) and separation (S) of the LLC. Dislocation (D) and separation (S) 6 weeks after trauma performed in internal rotation were compared with the values of internal and external rotation of the initial MRI scan to determine whether the LLC stayed in an anatomic position. All measures were performed with the syngo fast View tool (Siemens Company, Munich, Germany). The Wilcoxon test for paired samples was used for statistical analysis, and a significance level was set at $p=0.05$. Data analysis was performed with SPSS 18 for Windows (SPSS Inc., Chicago, IL).

After taking off the brace ( 3 weeks), no specific physiotherapeutic schema was instituted. The patients were advised to exercise the shoulder within the whole range of motion on their own but without forced internal rotation until the sixth week after dislocation. The patients were also recommended to refrain from contact sports for 3 months. After 6 weeks, a routine examination was performed for provisional control of success. Then, all patients were contacted by phone or by mail 5 years after the initial dislocation (May 2009-May 2011) and invited for a clinical follow-up examination. All patients were interviewed with regard to the subjectively experienced functional status of their shoulder, recurrent dislocation, subluxations, intermittent surgery, and history of any further shoulder trauma since ending immobilization. To investigate the functional status and, eventually, to reveal symptomatic or asymptomatic instabilities of the shoulder, a careful examination was performed at the affected side and the contralateral side using instability tests, such as the sulcus sign, apprehension and relocation test. Furthermore, the Constant and Murley score (CS) [9] and Rowe score (RS) [10] for both shoulders and the Western Ontario Shoulder Instability Index (WOSI) [11] for the affected shoulder were evaluated. The clinical examination and the clinical scores were performed by a medical doctor experienced in

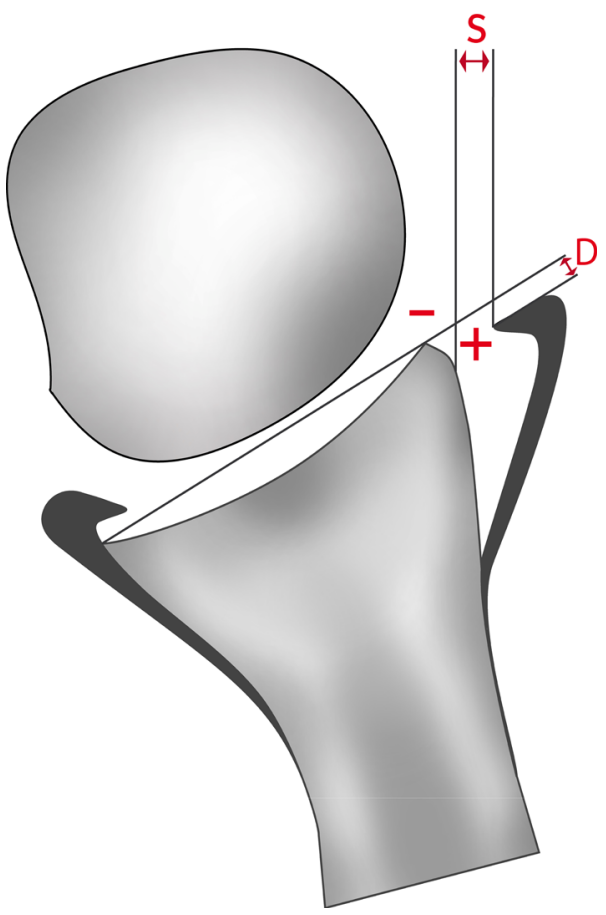

Fig. 3 Dislocation $(D)$ and separation $(S)$ of the labrum in relation to the glenoid rim (labral lesion). Positive values $(+)$ mean dislocation medially and separation anteriorly. Negative values $(-)$ indicate an increased reduction in the labrum over the articular glenoid surface (separation) or toward the humeral head (dislocation)

shoulder examination who was not involved in the initial treatment.

This study was approved by our institution's Medical Ethics Committee.

\section{Results}

MRI studies accomplished between May 2004 and May 2006 after initial trauma showed that in all examined
Fig. 2 Principle of immobilization in external rotation after primary traumatic dislocation of the shoulder (a). The labroligamentous lesion (yellow arrow) is reduced to the glenoid rim by external rotation with simultaneous shift of the effusion posteriorly (b) (color figure online)
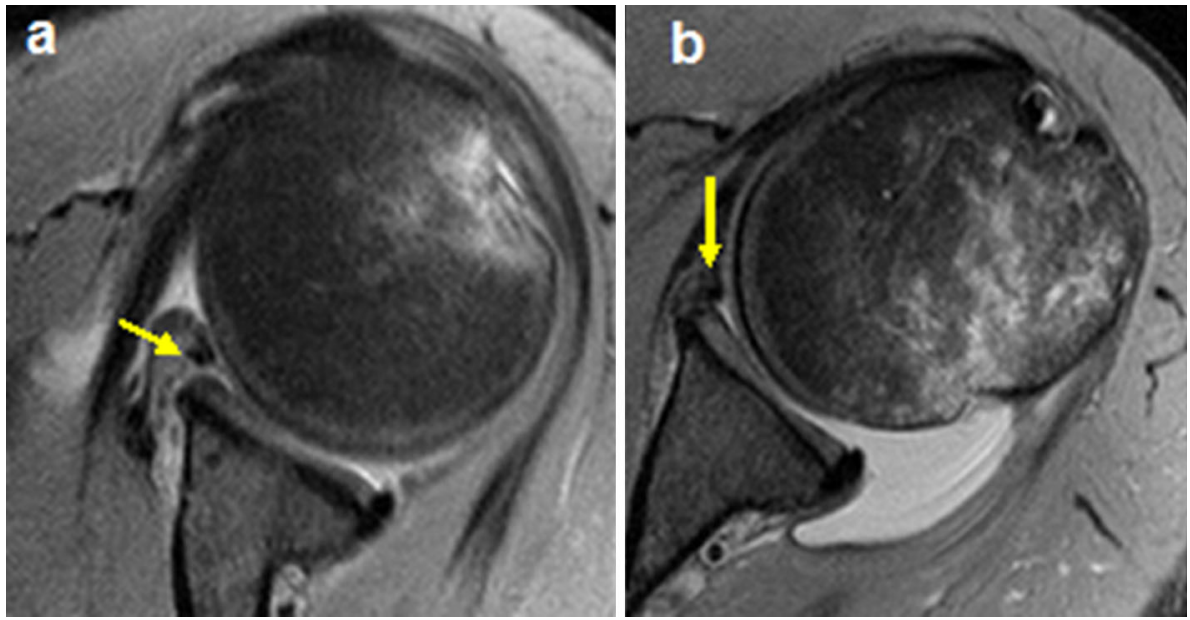
patients the position of the labrum relative to the glenoid rim improved significantly with external rotation versus internal rotation ( $p=0.001$ for dislocation, $p=0.011$ for separation of the LLC; see also Fig. 3). Six weeks later, after completing immobilization, the LLC was found to be fixed in the same position in 23 patients who returned for a new MRI image, while positioning the shoulder in internal rotation. Thus, compared to the imaging in external rotation after trauma, no significant difference was detected with the imaging of internal rotation with respect to dislocation $(p=0.057) 6$ weeks later. In contrast, the separation showed a significant improvement in the labrum position $(p=0.005)$.

Twenty-six of the 28 patients $(93 \%$ follow-up rate; $n=25$ males; $n=1$ female; mean age, $29.3 \pm 8.8$ years, 15-45 years) could be interviewed via phone call between May 2009 and May 2011 regarding re-dislocations 5 years after initial shoulder dislocation. Two patients (7\%) could not be contacted via phone or mail and were lost to followup. Of the 26 patients contacted by phone, two patients reported having very good shoulder function without sustaining a recurrent dislocation or subluxation. However, these patients did not want to continue the follow-up visits and refused further evaluation. As mentioned above, three patients were not invited for follow-up examination because of a re-dislocation and subsequent arthroscopic surgery of the shoulder in the interim. Thus, $21(75 \%$; $n=20$ male, $n=1$ female) of the 28 patients initially included in the study were re-examined clinically. Four of these patients refused to appear in person but agreed to complete a questionnaire by mail (self-evaluation Constant score [12], WOSI [11]). The Rowe score could not be evaluated in these four patients because the necessary instability test could not be performed by the examiner.

The mean interval between the dislocation and the beginning of the immobilization treatment in external rotation was $7.4 \pm 3.8$ days (range, 1-14 days). Six of the 28 patients $(21.4 \%)$ reported that they took off the brace not only for personal hygiene but also for other occasions (i.e., at night, driving a car). The average daily amount of time of immobilization was $22 \mathrm{~h}$ (range, 15-24 h). The right shoulder was affected in $54 \%(n=15)$ of the patients, and the left shoulder was affected in $46 \%$ $(n=13)$ of the cases.

Of the 26 patients included for the 5-year follow-up examination, four suffered a recurrent dislocation within the following period after the end of immobilization ( $\phi$ 12.2 month after initial dislocation), which corresponds to $15 \%$ of all re-dislocations. In three of the four patients, the recurrence occurred within the first year after initial immobilization. In the fourth patient, the shoulder re-dislocated 24 months after the bracing treatment. In all patients, the re-dislocation was caused by a minor trauma with the arm in abduction and external rotation (Table 1). All patients who sustained a re-dislocation were younger than 30 years at the initial trauma and at the time of recurrence, which corresponds to a recurrence rate of $25 \%$ of all patients younger than 30 years of age $(n=4 / 16)$. Consequently, three patients underwent arthroscopic Bankart repair after the second dislocation (Fig. 4). Patient 3 (Table 1) refused to undergo an operative treatment after the first re-dislocation (Fig. 5). During the follow-up examination, the patient reported " $6-7$ further dislocations" within the last 5 years. Nonetheless, he did not desire operative treatment or further diagnostic examinations.

The mean CS at the time of follow-up was $92.8 \pm 9.0$ points compared to $96.2 \pm 5.0$ points for the unaffected shoulder. The mean WOSI was $87 \pm 15.3 \%$, and the mean RS was $94.2 \pm 12.3$ points. One patient (45 years; daily wearing time of brace: $20 \mathrm{~h}$ ) with a positive apprehension and relocation test was identified, and therefore, the shoulder of this patient was also considered unstable. However, re-dislocations did not occur during the whole time in this patient. Although the patient reported that he did well in his activities of daily life, he also refused further diagnostics or therapy at the time of follow-up examination. Also, he showed worse results in the CS and in the instability scores compared to the other study participants (CS: 63.5 points; WOSI: $41 \%$; RS: 70 points). Including this patient with the other four patients with re-dislocation, the overall rate of instability is $19 \%$ at the 5-year followup within the study group. Complications related to the treatment in the external rotation brace were not observed.

\section{Discussion}

Due to high rates of recurrence after traditional immobilization in internal rotation after primary traumatic dislocation (e.g., with Gilchrist sling) [13, 14], a new method of immobilization in external rotation was presented in 1999 by Itoi et al. [1], who questioned the classical method of immobilization in internal rotation based on a cadaver study. This study showed for the first time that external rotation of the shoulder leads to repositioning of the LLC lesion on the glenoid neck. In another study in 2004, Miller et al. proved using a cadaver shoulder that increasing external rotation results in increased contact force of the labroligamentous lesion on the glenoid rim with a maximum contact force at $45^{\circ}$ [15]. These findings were subsequently confirmed in MRI-based studies in patients. In 2001, Itoi et al. [2] reported a significantly lower separation and dislocation of the labrum in external rotation in relation to internal rotation. To demonstrate these observations in our own patient population, we initiated an MRI study in 
Table 1 Patients with recurrence after immobilization in external rotation after primary traumatic anterior dislocation of the shoulder

\begin{tabular}{|c|c|c|c|c|c|c|c|c|}
\hline Patients & $\begin{array}{l}\text { Age at primary } \\
\text { dislocation }(y)\end{array}$ & $\begin{array}{l}\text { Cause/shoulder } \\
\text { side }\end{array}$ & $\begin{array}{l}\text { Labrum } \\
\text { lesion }\end{array}$ & $\begin{array}{l}\text { Interval } \\
\text { trauma/brace } \\
\text { (days) }\end{array}$ & $\begin{array}{l}\text { Time of } \\
\text { using the } \\
\text { brace }\end{array}$ & $\begin{array}{l}\text { Interval until } \\
\text { recurrence } \\
(\mathrm{mo})\end{array}$ & $\begin{array}{l}\text { Cause of } \\
\text { recurrence }\end{array}$ & $\begin{array}{l}\text { Surgery } \\
\text { after } \\
\text { recurrence }\end{array}$ \\
\hline $\begin{array}{l}\text { Patient } \\
1(\mathrm{~m})\end{array}$ & 16 & Fall/r & $\begin{array}{l}\text { Perthes } \\
\text { lesion }\end{array}$ & 1 & $3 \mathrm{w} / 22 \mathrm{~h} / \mathrm{d}$ & 10 & $\begin{array}{l}\text { Overhead } \\
\text { throw in } \\
\text { volleyball }\end{array}$ & Yes \\
\hline $\begin{array}{l}\text { Patient } \\
2(\mathrm{~m})\end{array}$ & 15 & $\mathrm{Fall} / \mathrm{r}$ & $\begin{array}{c}\text { Bankart } \\
\text { lesion }\end{array}$ & 8 & $3 \mathrm{w} / 24 \mathrm{~h} / \mathrm{d}$ & 12 & Weight training & Yes \\
\hline $\begin{array}{r}\text { Patient } \\
3(\mathrm{~m})\end{array}$ & 27 & Fall in football/r & $\begin{array}{l}\text { Perthes } \\
\text { lesion }\end{array}$ & 5 & $3 \mathrm{w} / 16 \mathrm{~h} / \mathrm{d}$ & 24 & $\begin{array}{l}\text { Abduction } \\
\text { move in } \\
\text { surfing }\end{array}$ & No \\
\hline $\begin{array}{r}\text { Patient } \\
4(\mathrm{~m})\end{array}$ & 16 & $\begin{array}{l}\text { Contact with } \\
\text { opponent in } \\
\text { handball/r }\end{array}$ & $\begin{array}{c}\text { Bankart } \\
\text { lesion }\end{array}$ & 9 & $3 \mathrm{w} / 24 \mathrm{~h} / \mathrm{d}$ & 3 & $\begin{array}{c}\text { Throwing } \\
\text { move in } \\
\text { handball }\end{array}$ & Yes \\
\hline
\end{tabular}

$m$ male, $y$ years of age, $r$ right, $w$ weeks, mo month

which we also found a significant difference in the labrum position relative to the glenoid cavity tangent comparing internal and external rotation [16]. Hart and Kelly verified the improved labrum position in external rotation in an arthroscopic examination and reported the best reduction of the labrum is $30^{\circ}$ of abduction and approximately $60^{\circ}$ of external rotation [17]. Then, for clinical practice, further details could be determined in subsequent studies on both the required duration of bracing in external rotation (3 weeks) [4] and immobilization (no difference between $15^{\circ}$ and $30^{\circ}$ external rotation) [5]. Furthermore, a wide acceptance of this special kind of immobilization was found within a treated group of patients [18].

Only a few clinical studies of immobilization in external rotation are available. An expanded prospective study was published by Itoi et al. in 2007. In this trial, the rate of recurrence was significantly lower within the group of bracing in external rotation compared to the group with internal rotation with an average follow-up of 25.6 months (Table 2). Additional calculations revealed a lowering of the relative risk of recurrence of about $38.2 \%$ in the patients treated with the external rotation brace compared to the patients with internal rotation. Especially in the critical age range of $<30$ years, a reduction in the relative risk of recurrence was achieved at approximately $46.1 \%$ [3]. For the first time, important questions have been raised in recent years regarding the method of immobilization in external rotation based on two further prospective trials, in which no benefit could been shown in relation to the rate of re-dislocations $[6,7]$. In the work by Finestone et al. [6], the rate of recurrent dislocations in a young, physically active male cohort ( $\phi 20.3$ years, range: $17-27$ years) in the external rotation group was $37 \%$, which contrasts with $41.7 \%$ in the internal rotation group. There was no significant difference between these two groups [6]. However, within the study by Itoi et al. [3], an older patient population (internal rotation: 37 years; external rotation: 35 years) was included. It is known that patients $<30$ years of age are at higher risk of re-dislocations regardless of the form of immobilization [3, 7, 19-21], which is also proven in the underlying study in relation to the whole study population ( 25 vs. $15 \%$ see above).

Recently, a large prospective multicenter study was presented by Liavaag et al., involving 184 patients [7]. The work revealed bracing in external rotation did not result in an advantage (Table 2). Moreover, no significant difference was found related to instability in the form of subluxations in the period after immobilization until the follow-up examination (external rotation: $38.3 \%$; internal rotation: $43.9 \%$ ), even if the occurrence of "subluxation" is certainly difficult to estimate retrospectively in each individual patient because of its subjective nature. Compared to Finestone et al. [6], there is a large significant result in the study by Liavaag et al. regarding the average age of the examined patient group, which at 27 years (16-40 years) is on average approximately 10 years younger than the cohort in the comparative study by Itoi et al. [3] and lies mostly in the age range with a higher incidence for primary shoulder dislocations [7].

Thus, regardless of the results achieved by Itoi et al., two other prospective control studies by different authors could not show a statistically significant advantage in the recurrence rate or clinical outcomes for external rotation when treating primary traumatic dislocation.

Within our patient population, four patients experienced a re-dislocation after 5 years due to minor trauma (15\%). At the time of primary trauma and re-dislocation, all of these patients were younger than 30 years of age (primary dislocation: $15-27$ years, $\phi 18.5$ years; re-dislocation: $15-29$ years, $\phi 19.5$ years), which corresponds to a rate of recurrence of $25 \%$ in patients $<30$ years of age $(n=$ $4 / 16$ ). Thus, the rate of recurrence lies below the results of 
Fig. 4 Patient 2: After primary dislocation, a Bankart lesion is detected in the MRI (a, yellow arrow). With external rotation, the labrum reduced sufficiently (b). After imaging 6 weeks later in internal rotation, the labroligamentous lesion is found to be reduced at the glenoid (c). After re-dislocation 12 months later, images reveal a consumed anterior labrum (d, arrow). Arthroscopy after recurrence confirms the scarred and frayed labrum at the anterior glenoid rim $(\mathbf{e}+\mathbf{f}$; red star: anterior glenoid rim; black star: humeral head; yellow star: raspatory) (color figure online)
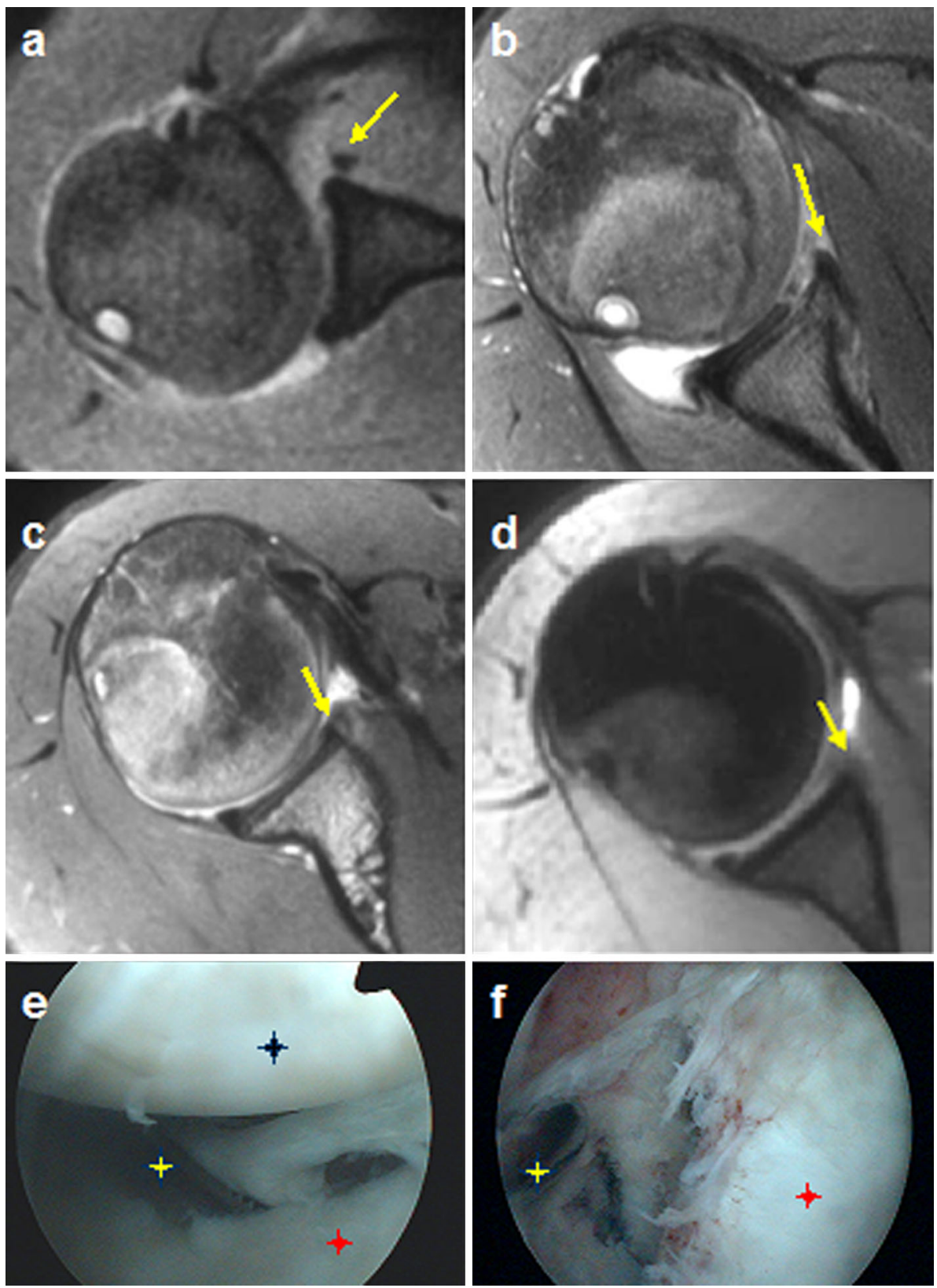

internal rotation in the literature at an equal age distribution $[13,14,22,23]$. In addition to the four re-dislocations, another patient was found to have symptomatic instabilities in the affected shoulder by clinical exam and in the clinical scores (Rowe score, WOSI). These five recurrent instabilities indicate a total instability of $19 \%$, which is comparable with previously described recurrence rates from other studies investigating immobilization in external rotation of shorter follow-up periods and in similar patients of average age $[3,4,7]$ (see also Table 2). As well as in the immobilization of internal rotation [22] or in the operative treatment groups [24], our data show that in external rotation the majority of re-dislocations occur within the first 2 years after initial trauma (3-24 months, $\phi 12.2$ months).

The specific reasons for the re-dislocation or instability remain difficult to determine. Various causes and circumstances can be discussed, such as insufficient compliance with wearing the external rotation brace for $24 \mathrm{~h}$ or 3 weeks, which cannot be controlled throughout the immobilization period despite patient reports. Furthermore, it is unclear what type of labroligamentous lesion (Bankart lesion, Perthes lesion, etc.) rather results in a possible recurrent instability. In an MRI analysis in patients with primary traumatic dislocation and detachment of the labrum, we found Perthes lesions that showed a low degree of plastic deformation that 
Fig. 5 Patient 3: Immediately after primary traumatic dislocation, MRI imaging demonstrates the labrum lesion at the antero-inferior glenoid rim with a Perthes lesion (arrow) and accompanied by effusion within the shoulder joint (a). External rotation (b) leads to a reduction in the labroligamentous lesion to the glenoid rim with a simultaneous shift of effusion posteriorly. The MRI after re-dislocation 2 years after primary dislocation and treatment in external rotation visualizes the labrum in terms of an ALPSA (anterior labral periosteal sleeve avulsion) lesion displaced medially (c, arrow). The temporal distance between re-dislocation and the MRI (c) was 1 week
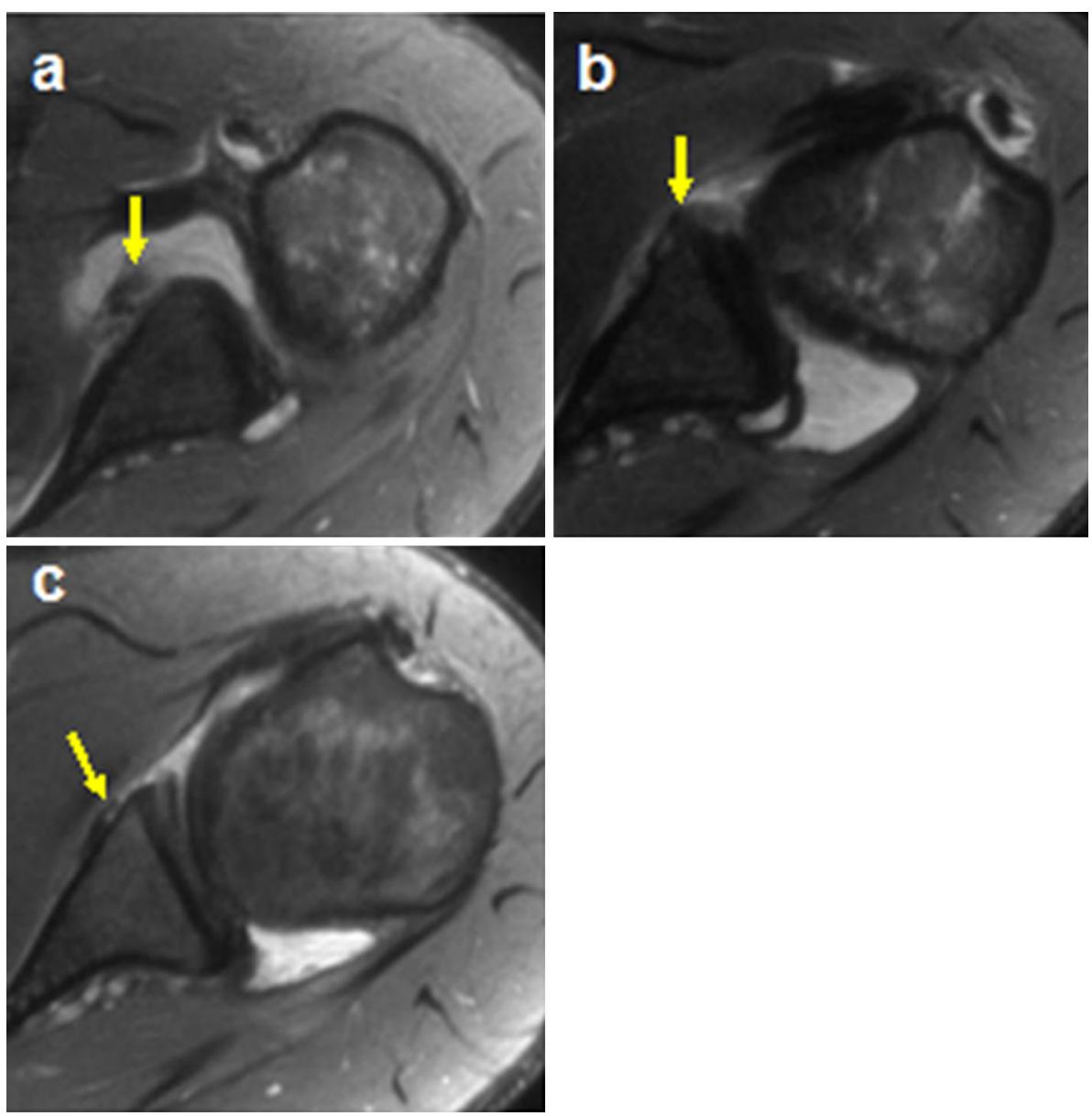

Table 2 Recurrence rate after conservative treatment for primary traumatic dislocation using immobilization in internal rotation and external rotation within prospective control studies

\begin{tabular}{|c|c|c|c|c|}
\hline Study & Recurrence (internal rotation) & Recurrence (external rotation) & $\phi$ Patients age (years) & $\phi$ Follow-up (months) \\
\hline \multicolumn{5}{|l|}{ Itoi et al. [3] } \\
\hline Intention-to-treat analysis & $42 \%(n=31 / 74)$ & $26 \%(n=22 / 85)$ & 36 & 25.6 \\
\hline Per-protocol analysis & $38 \%(n=15 / 39)$ & $20 \%(n=12 / 61)$ & & \\
\hline Finestone et al. [6] & $41.7 \%(n=10 / 24)$ & $37 \%(n=10 / 27)$ & 20.3 & 33.4 \\
\hline \multicolumn{5}{|l|}{ Liavaag et al. [7] } \\
\hline Intention-to-treat analysis & $24.7 \%(n=23 / 93)$ & $30.8 \%(n=28 / 91)$ & 26.8 & 29.1 \\
\hline Per-protocol analysis & $13.6 \%(n=6 / 44)$ & $21.7 \%(n=13 / 60)$ & & \\
\hline Total (Per-protocol) & $29 \%(n=31 / 107)$ & $23.6 \%(n=35 / 148)$ & 27.7 & 29.4 \\
\hline
\end{tabular}

displayed better reduction in external rotation compared to other lesions with high grade of plastic deformation [25]. However, the four patients with re-dislocation did not show uniform morphology of the labroligamentous lesion (two patients with Perthes lesions, two patients with Bankart lesions). Thus, the present study cannot make a prediction concerning the type and morphology of the labral lesion or about the healing rate in external rotation due to the low number of cases of re-dislocations.
Also, the timing between the primary dislocation and the immobilization treatment must be considered regarding the reduction and the healing of the detached labrum. Scarred changes of the labrum in the early stage after the trauma may negatively affect the healing at the glenoid rim. At least, the temporal distance between the first trauma and using the external rotation brace did not appear to make any difference in patient 1 (bracing in external rotation on the next day after dislocation). 
Nevertheless, the non-operative treatment in external rotation must be measured with operative treatment regarding recurrences and clinical outcome. The most recently published studies by Finestone et al. [6] and Liavaag et al. [7] deemed the operative treatment to be the more efficient treatment for primary traumatic dislocation, even though a direct comparison between immobilization in external rotation and surgery is not available as a randomized controlled trial. In contrast to immobilization in internal rotation, recurrence rates of operative treatment are clearly superior [24, 26-28]. Although the risks for surgery, especially in arthroscopic stabilization, are low [2830], these risks have to be considered and disclosed to the patient during the decision-making process. Moreover, the $19 \%$ with instability after 5 years should be critically discussed despite the good results of the remaining patients. However, it is notable that approximately $80 \%$ of the patients did not need a surgical therapy but would have underwent an operation without a clear need for an operative intervention if the primary traumatic dislocation was initially considered an indication for surgery. The data presented here show that the conservative procedure in external rotation has led to good results in most of the patients. In our eyes, the immobilization in external rotation is further indicated as the primary therapy for the first traumatic dislocation. In conclusion, the advantages and disadvantages of each treatment should be pointed out adequately to the patient considering the individual demands and the age of the patient as well as the operational experience of the treating physician.

This study has several limitations. For direct comparison of the methods of internal and external rotation, a control group with patients treated with internal rotation would have been necessary. However, due to a lack of a control group, our comparison was made using the literature. Also, more recent MRI findings of the affected shoulders within the 5-year follow-up would have provided more information about the position and healing of the labrum compared to previous findings. However, many patients were naturally unwilling to be re-imaged for research purposes and there was no indication in the absence of symptoms. Another limitation is that at the time of patient enrollment (2004-2006), the period between initial trauma and immobilization was defined generously with a range of 0-14 days. Nevertheless, with an average of 7 days until immobilization, the percentage of recurrent instability did not increase compared to other studies in the literature, which applied a lower interval of trauma/immobilization period (see above).

After the first clinical results by Itoi et al. in 2003 [31] and 2007 [3], it seemed that the new method of external rotation would lead to very good results. But the initial enthusiasm has been dampened by the recent published results of the above mentioned Scandinavian study [7]. Whether operative therapy is superior to non-operative treatment in external rotation for primary traumatic shoulder dislocation is subject to further investigations. Until clear data exist, we believe that immobilization in external rotation continues to be a reliable non-operative alternative to surgical treatment in primary traumatic shoulder dislocation at the present time.

\section{Conclusion}

Immobilization in external rotation of the shoulder for treatment for primary traumatic dislocation remains controversial given the varying recommendations in the current literature. This study shows that bracing in external rotation for 3 weeks leads to success over a period of 5 years in many patients. In our opinion, an important criterion for success is patient compliance with wearing the brace continuously within the prescribed period of time as well as the use of the brace in external rotation as early as possible after trauma. Whether the surgical treatment is more advantageous than external rotation regarding re-dislocations and rates of instability remains to be seen in the future. This conservative method in external rotation should be further on recommended as an alternative to an operation when assessing therapeutic choices during patient counseling.

\section{Conflict of interest None.}

\section{References}

1. Itoi E, Hatakeyama Y, Urayama M, Pradhan RL, Kido T, Sato K (1999) Position of immobilization after dislocation of the shoulder. A cadaveric study. J Bone Joint Surg Am 81:385-390

2. Itoi E, Sashi R, Minagawa H, Shimizu T, Wakabayashi I, Sato K (2001) Position of immobilization after dislocation of the glenohumeral joint. A study with use of magnetic resonance imaging. J Bone Joint Surg Am 83-A:661-667

3. Itoi E, Hatakeyama Y, Sato T, Kido T, Minagawa H, Yamamoto N, Wakabayashi I, Nozaka K (2007) Immobilization in external rotation after shoulder dislocation reduces the risk of recurrence. A randomized controlled trial. J Bone Joint Surg Am 89: 2124-2131. doi:10.2106/JBJS.F.00654

4. Scheibel M, Kuke A, Nikulka C, Magosch P, Ziesler O, Schroeder RJ (2009) How long should acute anterior dislocations of the shoulder be immobilized in external rotation? Am J Sports Med 37:1309-1316. doi:10.1177/0363546509331943

5. Seybold DGC, Schliemann B, Muhr G, Kälicke T (2008) How much external rotation is needed for immobilizing acute anterior shoulder dislocation in external rotation? Obere Extremität 4:214-218

6. Finestone A, Milgrom C, Radeva-Petrova DR, Rath E, Barchilon V, Beyth S, Jaber S, Safran O (2009) Bracing in external rotation for traumatic anterior dislocation of the shoulder. J Bone Joint Surg Br 91:918-921. doi:10.1302/0301-620X.91B7.22263 
7. Liavaag S, Brox JI, Pripp AH, Enger M, Soldal LA, Svenningsen $S$ (2011) Immobilization in external rotation after primary shoulder dislocation did not reduce the risk of recurrence: a randomized controlled trial. J Bone Joint Surg Am 93:897-904. doi: 10.2106/JBJS.J.00416

8. Gerber C, Nyffeler RW (2002) Classification of glenohumeral joint instability. Clin Orthop Relat Res 400:65-76

9. Constant CR, Murley AH (1987) A clinical method of functional assessment of the shoulder. Clin Orthop Relat Res 214:160-164

10. Rowe CR, Patel D, Southmayd WW (1978) The Bankart procedure: a long-term end-result study. J Bone Joint Surg Am 60:1-16

11. Kirkley A, Griffin S, McLintock H, Ng L (1998) The development and evaluation of a disease-specific quality of life measurement tool for shoulder instability. The Western Ontario Shoulder Instability Index (WOSI). Am J Sports Med 26:764-772

12. Boehm D, Wollmerstedt N, Doesch M, Handwerker M, Mehling E, Gohlke F (2004) Development of a questionnaire based on the Constant-Murley-Score for self-evaluation of shoulder function by patients. Unfallchirurg 107:397-402. doi:10.1007/s00113004-0757-3

13. Lill H, Verheyden P, Korner J, Hepp P, Josten C (1998) Conservative treatment after first traumatic shoulder dislocation. Chirurg 69:1230-1237

14. Hovelius L, Augustini BG, Fredin H, Johansson O, Norlin R, Thorling J (1996) Primary anterior dislocation of the shoulder in young patients. A ten-year prospective study. J Bone Joint Surg Am 78:1677-1684

15. Miller BS, Sonnabend DH, Hatrick C, O'Leary S, Goldberg J, Harper W, Walsh WR (2004) Should acute anterior dislocations of the shoulder be immobilized in external rotation? A cadaveric study. J Shoulder Elbow Surg 13:589-592. doi:10.1016/S105827 4604001211

16. Seybold D, Gekle C, Fehmer T, Pennekamp W, Muhr G, Kalicke $\mathrm{T}$ (2006) Immobilization in external rotation after primary shoulder dislocation. Chirurg 77:821-826. doi:10.1007/s00104006-1181-8

17. Hart WJ, Kelly CP (2005) Arthroscopic observation of capsulolabral reduction after shoulder dislocation. J Shoulder Elbow Surg 14:134-137. doi:10.1016/j.jse.2004.07.002

18. Schliemann B, Seybold D, Muhr G, Gekle C (2009) Immobilisation of the shoulder in external rotation after traumatic firsttime dislocation-what is reasonable? A retrospective survey. Sportverletz Sportschaden 23:100-105. doi:10.1055/s-00281109418

19. Robinson CM, Kelly M, Wakefield AE (2002) Redislocation of the shoulder during the first six weeks after a primary anterior dislocation: risk factors and results of treatment. J Bone Joint Surg Am 84-A:1552-1559
20. Rowe CR, Sakellarides HT (1961) Factors related to recurrences of anterior dislocations of the shoulder. Clin Orthop 20:40-48

21. Hoelen MA, Burgers AM, Rozing PM (1990) Prognosis of primary anterior shoulder dislocation in young adults. Arch Orthop Trauma Surg 110:51-54

22. Robinson CM, Howes J, Murdoch H, Will E, Graham C (2006) Functional outcome and risk of recurrent instability after primary traumatic anterior shoulder dislocation in young patients. J Bone Joint Surg Am 88:2326-2336. doi:10.2106/JBJS.E.01327

23. Kralinger FS, Golser K, Wischatta R, Wambacher M, Sperner G (2002) Predicting recurrence after primary anterior shoulder dislocation. Am J Sports Med 30:116-120

24. Robinson CM, Jenkins PJ, White TO, Ker A, Will E (2008) Primary arthroscopic stabilization for a first-time anterior dislocation of the shoulder. A randomized, double-blind trial. J Bone Joint Surg Am 90:708-721. doi:10.2106/JBJS.G.00679

25. Seybold D, Schliemann B, Heyer CM, Muhr G, Gekle C (2009) Which labral lesion can be best reduced with external rotation of the shoulder after a first-time traumatic anterior shoulder dislocation? Arch Orthop Trauma Surg 129:299-304. doi:10.1007/ s00402-008-0618-6

26. Brophy RH, Marx RG (2009) The treatment of traumatic anterior instability of the shoulder: nonoperative and surgical treatment. Arthroscopy 25:298-304. doi:10.1016/j.arthro.2008.12.007

27. Bottoni CR, Smith EL, Berkowitz MJ, Towle RB, Moore JH (2006) Arthroscopic versus open shoulder stabilization for recurrent anterior instability: a prospective randomized clinical trial. Am J Sports Med 34:1730-1737. doi:10.1177/03635465062 88239

28. Van Tongel A, Rosa F, Heffernan G, Levy O, Sforza G (2011) Long-term result after traumatic anterior shoulder dislocation: what works best? Musculoskelet Surg 95(Suppl 1):S65-S70. doi: 10.1007/s12306-011-0125-8

29. Law BK, Yung PS, Ho EP, Chang JJ, Chan KM (2008) The surgical outcome of immediate arthroscopic Bankart repair for first time anterior shoulder dislocation in young active patients. Knee Surg Sports Traumatol Arthrosc 16:188-193. doi:10.1007/ s00167-007-0453-2

30. Ozbaydar M, Elhassan B, Diller D, Massimini D, Higgins LD, Warner JJ (2008) Results of arthroscopic capsulolabral repair: Bankart lesion versus anterior labroligamentous periosteal sleeve avulsion lesion. Arthroscopy 24:1277-1283. doi:10.1016/j.arthro. 2008.01.017

31. Itoi E, Hatakeyama $\mathrm{Y}$, Kido $\mathrm{T}$, Sato $\mathrm{T}$, Minagawa $\mathrm{H}$, Wakabayashi I, Kobayashi M (2003) A new method of immobilization after traumatic anterior dislocation of the shoulder: a preliminary study. J Shoulder Elbow Surg 12:413-415. doi:10.1016/S10582 $7460300171 \mathrm{X}$ 